\title{
Redundant role of the cytochrome $c$-mediated intrinsic apoptotic pathway in pancreatic $\beta$-cells
}

\author{
Diana Choi ${ }^{1, *}$, Stephanie A Schroer ${ }^{1}, *$, Shun Yan Lu ${ }^{1}$, Erica P Cai ${ }^{2}$, Zhenyue Hao ${ }^{1}$ and Minna Woo ${ }^{1,2,3,4}$ \\ ${ }^{1}$ Ontario Cancer Institute, University of Toronto, 610 University Avenue, Toronto, Ontario M5G 2M9, Canada \\ ${ }^{2}$ Institute of Medical Science, University of Toronto, Toronto, Ontario M5G 2M9, Canada \\ ${ }^{3}$ Department of Medicine and ${ }^{4}$ Keenan Research Centre in the Li Ka Shing Knowledge Institute, St Michael's Hospital, Toronto, Ontario M3B 1W5, Canada \\ (Correspondence should be addressed to M Woo at Ontario Cancer Institute, University of Toronto; Email: mwoo@uhnres.utoronto.ca) \\ *(D Choi and S A Schroer contributed equally to this work)
}

\begin{abstract}
Cytochrome $c$ is one of the central mediators of the mitochondrial or the intrinsic apoptotic pathway. Mice harboring a 'knock-in' mutation of cytochrome $c$, impairing only its apoptotic function, have permitted studies on the essential role of cytochrome $c$-mediated apoptosis in various tissue homeostasis. To this end, we examined the role of cytochrome $c$ in pancreatic $\beta$-cells under homeostatic conditions and in diabetes models, including those induced by streptozotocin (STZ) and c-Myc. Previous studies have shown that both STZ- and c-Myc-induced $\beta$-cell apoptosis is mediated through caspase- 3 activation; however, the precise mechanism in these modes of cell death was not characterized.
\end{abstract}

The results of our study show that lack of functional cytochrome $c$ does not affect glucose homeostasis or pancreatic $\beta$-cell mass under basal conditions. Moreover, the cytochrome $c$-mediated intrinsic apoptotic pathway is required for neither STZ- nor c-Myc-induced $\beta$-cell death. We also observed that the extrinsic apoptotic pathway mediated through caspase- 8 was not essential in c-Myc-induced $\beta$-cell destruction. These findings suggest that cytochrome $c$ is not required for STZ-induced $\beta$-cell apoptosis and, together with the caspase-8-mediated extrinsic pathway, plays a redundant role in c-Myc-induced $\beta$-cell apoptosis.

Journal of Endocrinology (2011) 210, 285-292

\section{Introduction}

Apoptosis is a genetically regulated cell suicide program, which is essential for multicellular organisms. It is necessary for embryonic development and adult tissue homeostasis by mediating elimination of unwanted cells, which can be potentially harmful (Thompson 1995, Jacobson et al. 1997). The process of apoptosis is tightly regulated in an orderly series of signal cascades under specific circumstances. The caspase cascade system plays a vital role in the induction, transduction, and amplification of intracellular apoptotic signals through two main pathways: the extrinsic and the intrinsic apoptotic pathways. In the extrinsic pathway (also known as death receptor pathway), apoptosis is triggered by ligand-induced activation of death receptors at the cell surface. On receptor ligation, procaspase- 8 is recruited to interact with its death domain to form the death-inducing signal complex, where it gets activated (Muzio et al. 1996). In the intrinsic pathway (also called mitochondrial pathway), apoptosis is activated in response to cellular stressors and results in an intracellular cascade of events in which mitochondrial permeabilization is perturbed and cytochrome $c$ is released to initiate the apoptotic signaling (Kuwana et al. 2002, Lakhani et al. 2006). Both pathways activate the apoptosis 'executioners' including caspases-3, -6 , and/or -7 , leading to the terminal phase of apoptosis (Woo et al. 2000, Zimmermann et al. 2001).

Our previous studies have shown the integral role of caspases- 3 and -8 in pancreatic $\beta$-cell apoptosis in experimental models of diabetes. Mice lacking caspase- 3 are protected from $\beta$-cell apoptosis and diabetes induced by both streptozotocin (STZ; Liadis et al. 2003) and c-Myc activation (Radziszewska et al. 2009). In addition, mice with $\beta$-cell-specific caspase- 8 deletion are protected against both STZ- and high-fat dietinduced models of diabetes (Liadis et al. 2007). Furthermore, neither caspase-3 nor caspase-8 appeared to be essential for $\beta$-cell homeostasis under physiological conditions. Collectively, these studies demonstrate that caspases -3 and -8 are essential in $\beta$-cell apoptosis leading to diabetes development.

Cytochrome $c$ has been primarily known for its function in the mitochondria as a key factor in the respiratory chain for ATP synthesis. However, on apoptotic stimulus, such as DNA damage, metabolic stress, or the presence of excess unfolded proteins, the intrinsic apoptotic pathway is triggered and the mitochondrial cytochrome $c$ is released into the cytosol (Liu et al. 1996, Kluck et al. 1997a,b, Yang et al. 1997). Cytoplasmic cytochrome $c$ engages the apoptotic protease-activating factor (APAF-1) to form the apoptosome (Li et al. 1997), 
which recruits procaspase-9 and promotes its efficient activation (Rodriguez \& Lazebnik 1999, Zou et al. 1999). Activated caspase-9 in turn activates the downstream effectors caspases-3, -6, and/or -7 , which rapidly cleave intracellular substrates. As well as its role in the canonical intrinsic apoptotic pathway, cytochrome $c$ release can also be activated through Bid, which is cleaved by caspase- 8 , which is activated by the extrinsic pathway ( $\mathrm{Li}$ et al. 1998), thereby amplifying the apoptotic signaling (Klefstrom et al. 2002). The importance of cytochrome $c$ in apoptosis has been assessed using a 'knock-in' approach in transgenic mice (Hao et al. 2005), whereby the mutation encodes for a cytochrome $c$ protein that retains normal respiratory function but lacks apoptotic function due to failure in oligomerizing APAF-1 and forming the apoptosome, which is required for procaspase- 9 activation. Elegant experiments using this mutant mouse model demonstrated that loss of cytochrome $c$-mediated apoptosis disturbs normal brain development and lymphocyte homeostasis (Hao et al. 2005). However, the role of this apoptotic pathway in pancreatic $\beta$-cells was not assessed.

The mitochondria are central to the maintenance of $\beta$-cell function (Silva et al. 2000, Lowell \& Shulman 2005) and are also an important mediator of $\beta$-cell apoptosis (Bruin et al. 2008, Holohan et al. 2008, Chen et al. 2009). However, the essential role of cytochrome $c$-mediated apoptosis in pancreatic $\beta$-cells under basal and diabetic conditions in vivo was not known. Basal $\beta$-cell apoptosis is known to play a role in the remodeling and development of the normal endocrine pancreas (Finegood et al. 1995). Excessive $\beta$-cell apoptosis is also a well-appreciated mode of cell death that contributes to both type 1 and type 2 diabetes (O'Brien et al. 1997, Donath et al. 2005). Mechanistic insights into the control of pancreatic $\beta$-cell apoptosis both during homeostatic conditions and during the course of diabetes development are therefore important for the prevention and treatment of diabetes.

Gene targeting strategies can provide valuable tools to study the physiological function and pathophysiological role of individual apoptotic mediators. In this study, the 'knock-in' mice expressing the mutant cytochrome $c$ (KA allele; Hao et al. 2005), which retains normal electron transfer function but fails to participate in the apoptosome formation, were used to assess the role of cytochrome $c$-mediated apoptotic pathway in pancreatic $\beta$-cells.

\section{Materials and Methods}

\section{Mouse protocol}

Cytochrome $c$ mutant mice $\left(C y t c^{\mathrm{KA} / \mathrm{KA}}\right)$ were generated previously (Hao et al. 2005) and contain the mutation of lysine 72 to alanine (K72A), which specifically abolishes the apoptotic function. $\mathrm{c}-\mathrm{M} Y c-E R \quad(T A M)\left(\mathrm{MYc}^{+}\right)$transgenic mice were generated as reported (Pelengaris et al. 2002), in which the $c-M \gamma c$ transgene in pancreatic $\beta$-cells is activated on tamoxifen injection. $C y t c^{\mathrm{KA} / \mathrm{KA}}$ mice were crossed to $\mathrm{Myc}^{+}$mice to obtain $\mathrm{Myc}^{-}, \mathrm{Myc}^{+} \mathrm{Cytc}^{+/+}, \mathrm{Myc}^{+} \mathrm{C}_{\mathrm{t}} \mathrm{c}^{+/ \mathrm{KA}}$, and $\mathrm{Myc}^{+} \mathrm{C} \gamma t \mathrm{c}^{\mathrm{KA} / \mathrm{KA}} \cdot \mathrm{Myc}^{+} \mathrm{C}_{t t c^{+/+}}$and $\mathrm{Myc}^{+} \mathrm{C} \gamma t c^{+/ \mathrm{KA}}$ littermates were used as controls for $M_{\gamma} c^{+} C_{\gamma t c^{\mathrm{KA} / \mathrm{KA}} \text { mice }}$ in all experiments. RIPcre ${ }^{+} \operatorname{Cas} p 8^{\mathrm{H} / \mathrm{fl}}$ mice were generated as previously described (Liadis et al. 2007), in which the tissuespecific deletion of caspase- 8 was under the control of the rat insulin promoter (RIP). $\mathrm{Myc}^{+}$mice were bred to RIPcre ${ }^{+}$ Casp $8^{\mathrm{A} / \mathrm{fl}}$ mice to generate $\mathrm{Myc}^{+} \mathrm{RIPcre}^{+} \mathrm{Casp}^{+/ \mathrm{fl}}$ mice, and these mice were then intercrossed to generate $\mathrm{Myc}^{+} \mathrm{RIPcre}^{+}$

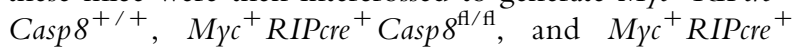
Casp $8^{+/ f}$ mice. Control mice for all experiments were $\mathrm{Myc}^{+} \mathrm{RIPcre}^{+} \mathrm{Casp}^{+/ \mathrm{fl}}$ or $\mathrm{MYc}^{+} \mathrm{RIPcre}^{+} \mathrm{Casp}^{+/+}$littermates. Mice were maintained on a $C 57 B L / 6$ background. Genotyping was performed by PCR with genomic DNA from ear or tail tissue as described previously (Salmena et al. 2003, Hao et al. 2005). The activity of the mice was not restricted, and they were maintained on a $12 \mathrm{~h}$ light: $12 \mathrm{~h}$ darkness cycle. All mice were fed regular chow (Harlan-Teklad, Mississauga, Ontario, Canada). Mice used in experiments were all 8-12 weeks of age unless indicated. All protocols were approved by the Ontario Cancer Institute, Animal Resource Colony.

\section{Induction of diabetes by STZ and glucose monitoring}

The mice were injected i.p. with multiple low doses of STZ (40 mg/kg body weight) for five consecutive days as described previously (Liadis et al. 2003). Blood glucose was measured weekly after the injection.

\section{Activation of $c-M \gamma c$}

The c-MYc-ER (TAM) transgene was activated by daily i.p injection of $1 \mathrm{mg}$ tamoxifen (Sigma) dissolved in peanut oil (Sigma), at a final concentration of $10 \mathrm{mg} / \mathrm{ml}$ in adult mice. Blood glucose levels were measured at specific time points.

\section{Metabolic studies}

Mice were fasted overnight for 14-16 h prior to experiments. Blood glucose levels were determined from tail venous blood. Glucose tolerance tests were performed on fasted mice using i.p. injected glucose at a dose of $2 \mathrm{~g} / \mathrm{kg}$ body weight. Insulin tolerance tests were performed using human regular insulin at a dose of $1 \mathrm{U} / \mathrm{kg}$ body weight i.p. injected. Blood glucose measurements were obtained at $0,15,30,45,60$, and $120 \mathrm{~min}$ after glucose or insulin injection.

\section{Immunohistochemistry, immunofluorescent staining, and islet morphometry}

Pancreata were isolated from mice at days 0,1 , and 30 after tamoxifen treatment. Pancreatic tissue was fixed for $24 \mathrm{~h}$ in $4 \%$ paraformaldehyde in $0.1 \mathrm{M}$ PBS ( $\mathrm{pH} 7 \cdot 4$ ). Samples were dehydrated and prepared as paraffin blocks. Sections $(7 \mu \mathrm{m}$ thick) were obtained at $150 \mu \mathrm{m}$ intervals on three levels and stained for insulin, Ki67 (DAKO, Burlington, Ontario, Canada), and TUNEL (ID Labs, London, Ontario, Canada). 

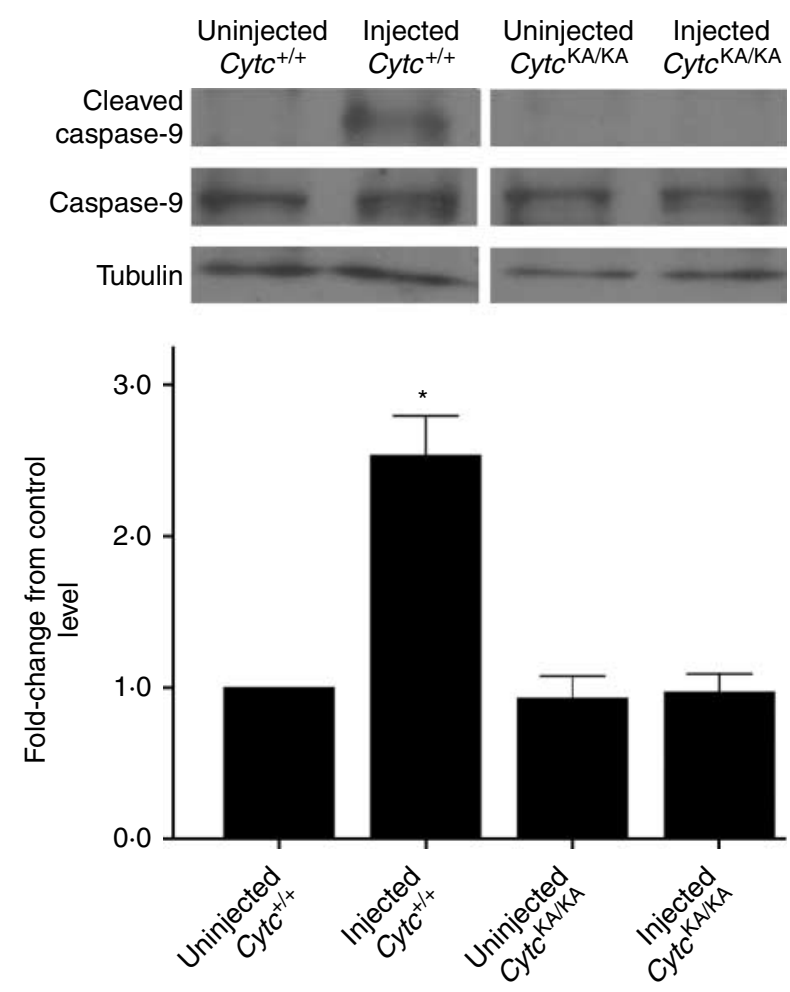

Figure 1 Cytochrome $c$ inactivation in the $C y t c^{\mathrm{KA} / K A}$ mice. Western blot analyses on isolated islets show increased cleaved caspase- 9 expression in the islets of $\mathrm{Cytc}^{+/+}$mice after c-Myc activation, whereas decreased cleaved caspase- 9 expression levels were observed in the islets of $C y t c^{\mathrm{KA} K A}$ mice after c-Myc activation for 1 day, $n=3$ per genotype. Results represent mean \pm S.E.M. ${ }^{*} P<0 \cdot 05$.

Total $\beta$-cell area and total pancreatic area were determined from insulin-immunostained sections by automated area counting and expressed as total $\beta$-cell area divided by total pancreatic area. Immunofluorescent staining was performed on sections to detect insulin (DAKO) and glucagon (Sigma), which were visualized using a Zeiss inverted fluorescent microscope (Toronto, Ontario, Canada).

\section{Statistical analysis}

Data are presented as mean \pm S.E.M. and were analyzed by one-sample $t$-test, independent samples $t$-test, and one-way ANOVA with the post hoc Tukey least significant difference test, where appropriate. Data were analyzed using the statistical package SPSS for Windows version 17.0.

\section{Results}

Lack of apoptotic function of cytochrome $\mathrm{c}$ in pancreatic islets has no effect on glucose homeostasis or $\beta$-cell mass

Mice with the cytochrome $c$ knock-in mutation (Cytc ${ }^{\mathrm{KA} / \mathrm{KA}}$ ) were born at a frequency of $12 \%$ from heterozygous breeding, which is about half of the expected Mendelian ratio, as previously reported (Hao et al. 2005). Surviving mice appeared generally healthy similar to previous observations (Hao et al. 2005). To confirm the absence of cytochrome $c$-mediated apoptotic activation in the $C y t c^{\mathrm{KA} / \mathrm{KA}}$ mice, we examined caspase- 9 cleavage by western blot analyses in the islets on apoptotic stimuli with c-Myc activation (to be discussed in detail in the next section). Activation of caspase-9 was absent in islets of $C y t c^{\mathrm{KA} / \mathrm{KA}}$ mice, as evidenced by a lack of cleavage of procaspase-9, confirming the lack of cytochrome $c$-mediated apoptosis in these mice (Fig. 1).

The intrinsic pathway is known to be involved in $\beta$-cell apoptosis (Thomas \& Biden 2009). However, it is not clear whether the cytochrome $c$-mediated apoptotic pathway is required for $\beta$-cell mass and glucose homeostasis. To assess the essential role of this apoptotic pathway in pancreatic $\beta$-cells, we performed metabolic studies and examined pancreatic morphology in Cytc $c^{\mathrm{KA} / \mathrm{KA}}$ mice. No differences were found in body weight (Fig. 2A) nor fed (Fig. 2B) or fasting blood glucose levels (Fig. 2C) between Cytc ${ }^{\mathrm{KA} / \mathrm{KA}}$ mice and their wild-type controls. Glucose tolerance and insulin tolerance tests also did not show any differences between the genotypes (Fig. 2D and E). $\beta$-Cell area was examined by insulin
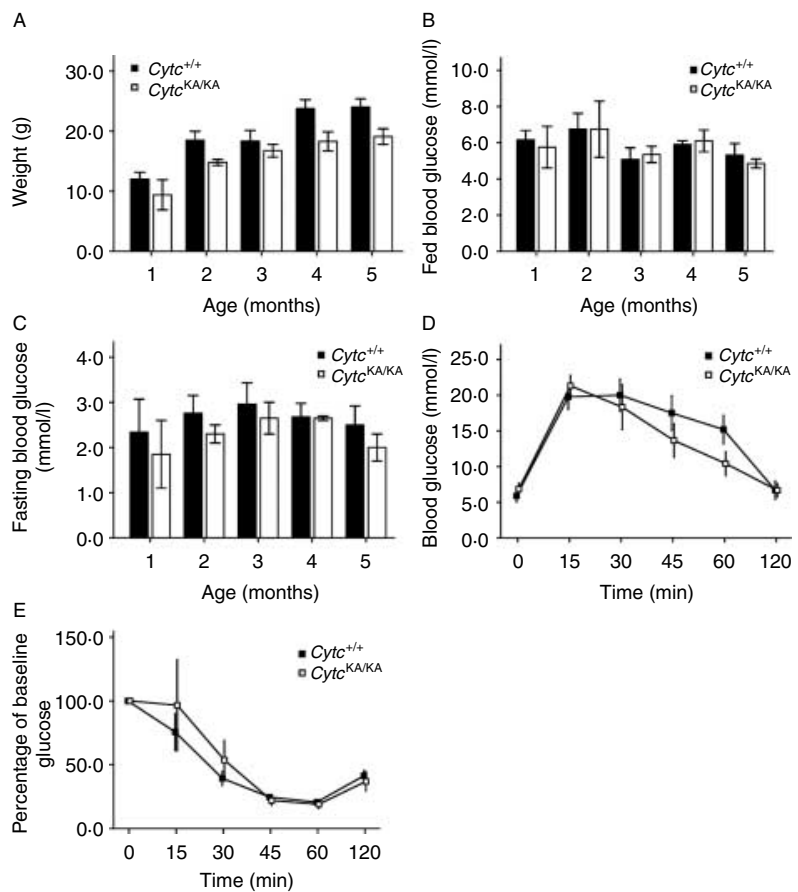

Figure 2 Lack of functional cytochrome $c$ did not affect glucose homeostasis. No differences were found in weight (A), fed blood glucose (B), or fasting blood glucose level (C) between $\mathrm{Myc}^{--}$ Cytc $^{+/+}$and $\mathrm{MyC}^{-}$Cytc $\mathrm{KA} / \mathrm{KA}^{\mathrm{mice}} n=8$ per genotype. In addition, glucose tolerance tests (GTTs) at a dose of $2 \mathrm{~g} / \mathrm{kg} \mathrm{BW,} \mathrm{(D)} \mathrm{and}$ insulin tolerance tests (ITTs) at a dose of $1 \mathrm{U} / \mathrm{kg} \mathrm{BW,} \mathrm{(E)} \mathrm{revealed} \mathrm{no}$ significant differences between the genotypes as well, $n=5$ per genotype. Mice used for the GTTs and ITTs were between 8 and 12 weeks of age. Abbreviation: $+/+, C y t C^{+/+} ; \mathrm{KA} / \mathrm{KA}, C y t c^{\mathrm{KA} / \mathrm{KA}}$. Results represent mean \pm S.E.M. 
A
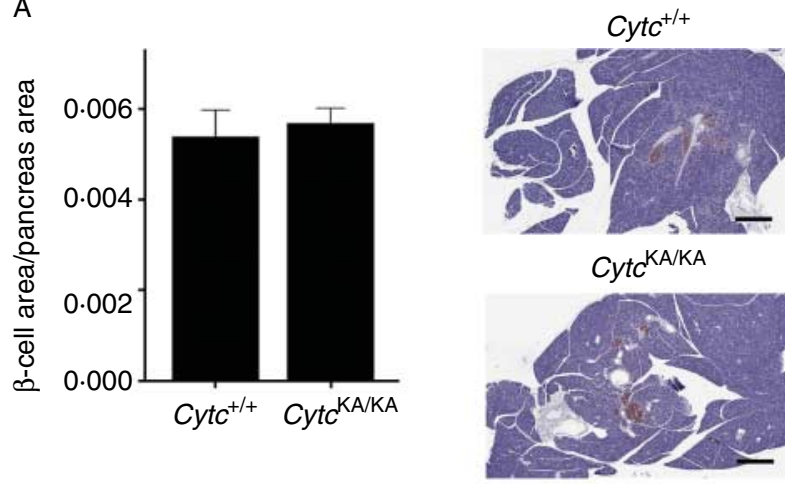

B
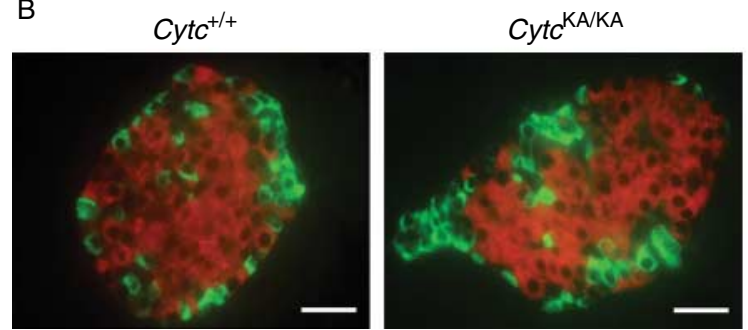

Insulin: red

Glucagon: green

Figure 3 Cytochrome $c$ did not play an essential role in regulating $\beta$-cell mass. (A) $\beta$-Cell area per pancreatic area analyses on insulinstained sections showed no difference between the genotypes, $n=3$ per genotype. Original magnification $\times 10$. Scale bars $=200 \mu \mathrm{m}$. Results represent mean \pm S.E.M. (B) Insulin and glucose double staining by immunofluorescence show intact islet architecture in the Cytc KA/KA mice, similar to controls, $n=3$ per genotype. All mice used in experiments were between 8 and 12 weeks of age. Original magnification $\times 20$. Scale bars $=40 \mu \mathrm{m}$.

immunostaining on pancreatic sections and calculated as a ratio per pancreatic area. No differences were found between the genotypes (Fig. 3A). In addition, islet architecture and morphology were also normal in $C y t c^{\mathrm{KA} / \mathrm{KA}}$ mice as examined by insulin and glucagon co-immunofluorescent staining (Fig. 3B). The normal glucose homeostasis and islet morphology in $C y t c^{\mathrm{KA} / \mathrm{KA}}$ mice show that the cytochrome $c$-mediated apoptotic pathway is not essential for $\beta$-cell mass determination or glucose homeostasis.

\section{Cytochrome c-mediated apoptotic pathway is not required for $S T Z$-induced diabetes and pancreatic $\beta$-cell destruction}

STZ is a glucose analog that selectively destroys pancreatic $\beta$-cells. Apoptosis is the major mode of cell death that is responsible for diabetes development in this model (Saini et al. 1996). To determine the essential role of the intrinsic pathway on STZ-induced $\beta$-cell apoptosis and diabetes in vivo, we subjected the mice to MLDS-induced diabetes. $C y t c^{\mathrm{KA} / \mathrm{KA}}$ mice developed diabetes as evidenced by increased blood glucose levels that were similar to their control counterparts (Fig. 4A). Insulin-immunostained pancreatic sections also showed similar decreases in $\beta$-cell area/pancreatic area between the genotypes (Fig. 4B). These results demonstrate that apoptosis in $\beta$-cells can proceed without the cytochrome $c$-mediated intrinsic apoptotic pathway at least in response to STZ.

Loss of the apoptotic function of cytochrome $\mathrm{c}$ does not confer protection against $c-M \gamma c$-induced $\beta$-cell apoptosis and diabetes

Overexpression of $\mathrm{c}-\mathrm{Myc}$ in the $\beta$-cells in mice results in rapid proliferation, followed by massive apoptosis, leading to fulminant diabetes and death shortly after birth (Laybutt et al. 2002). To circumvent this early lethality and to enable investigating the role of c-Myc in $\beta$-cells in adult mice, an inducible transgenic mouse expressing modified estrogen receptor ligand-binding domain fused to the human c-myc gene was generated. This mouse allows for the $c-M \gamma c$ transgene expression to be 'switched on' in $\beta$-cells in the presence of tamoxifen (Pelengaris et al. 2002). We crossed this transgenic mouse to $C y t c^{\mathrm{KA} / \mathrm{KA}}$ mice to generate $\mathrm{Myc}^{+} \mathrm{C} y t^{\mathrm{KA} / \mathrm{KA}}$ mice to test whether the cytochrome $c$-mediated apoptotic pathway plays a role in c-Myc-induced $\beta$-cell apoptosis and diabetes.

$\mathrm{Myc}^{+} \mathrm{Cytc}{ }^{\mathrm{KA} / \mathrm{KA}}$ mice and their control $\mathrm{Myc}^{+} \mathrm{Cytc}^{+/+}$ mice littermates were injected with tamoxifen for 30 consecutive days to sustain the activation of $\mathrm{c}-\mathrm{Myc}$ in the pancreatic $\beta$-cells. $\mathrm{Myc}^{+} \mathrm{Cytc}^{+/+}$mice developed hyperglycemia on c-Myc activation as early as day 3 of injection, similar to $\mathrm{Myc}^{+} \mathrm{C} \gamma t c^{\mathrm{KA} / \mathrm{KA}}$ mice, and they reached similar degree of hyperglycemia (Fig. 5A), suggesting that cytochrome $c$-mediated apoptosis was not essential in c-Mycinduced diabetes. Pancreatic sections immunostained for insulin showed reduced $\beta$-cell area and near ablation of islets in both genotypes (Fig. 5B).

We assessed pancreatic sections for Ki67- and TUNELpositive islet cells after 2 days of tamoxifen injection to determine the role of cytochrome $c$ in c-Myc-induced islet proliferation and apoptosis respectively. We observed similar
A

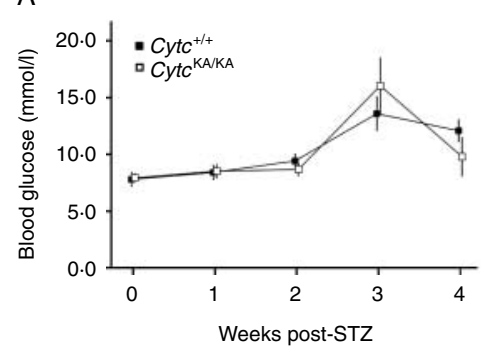

B

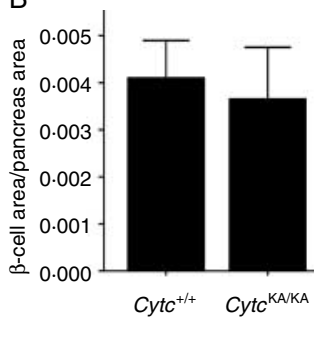

Figure 4 Loss of cytochrome $c$-mediated apoptosis did not confer protection against STZ-induced diabetes and $\beta$-cell destruction. (A) Random blood glucose monitored weekly after five consecutive daily i.p. injections of low-dose STZ (50 $\mu \mathrm{g} / \mathrm{kg} \mathrm{BW),} n=8$ per genotype. (B) Insulin immunostaining shows no differences in $\beta$-cell area per pancreatic area between the STZ-treated $C y t c^{\mathrm{KA} / \mathrm{KA}}$ mice and the Cytc ${ }^{+/+}$mice, $n=5$ per genotype. All mice used in experiments were between 8 and 12 weeks of age. Results represent mean \pm S.E.M. 


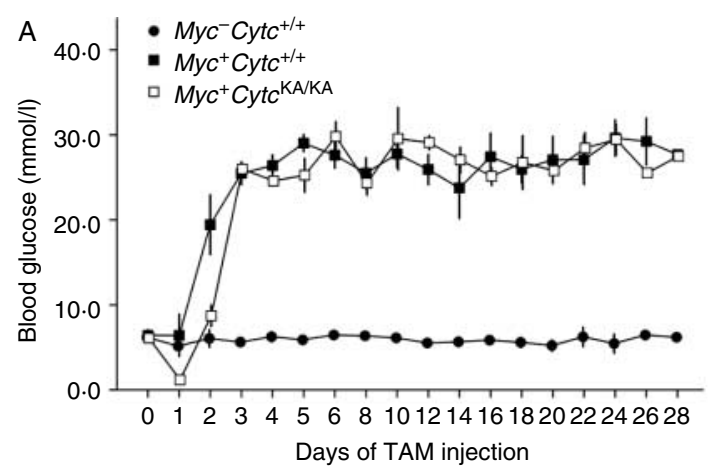

B $\mathrm{Myc}^{-} \mathrm{Cytc}^{+/+}$

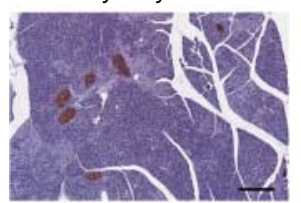

$\mathrm{Myc}^{+} \mathrm{Cytc}^{+/+}$

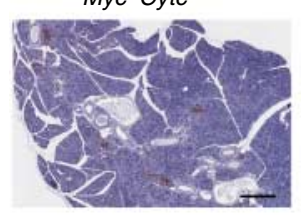

$\mathrm{Myc}^{+} \mathrm{Cytc}^{\mathrm{KA} / \mathrm{KA}}$
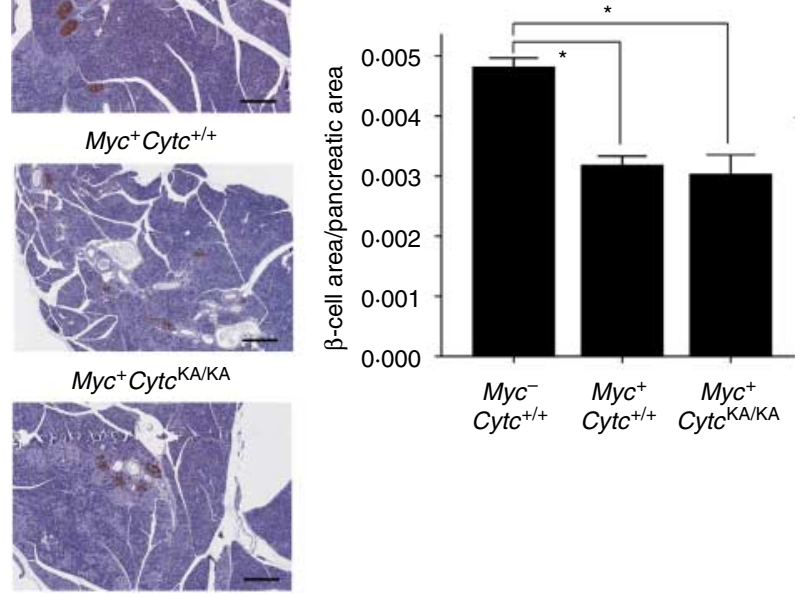

Figure 5 The cytochrome $c$-mediated intrinsic apoptotic pathway is not required for $\mathrm{C}-\mathrm{Myc}$-induced diabetes and $\beta$-cell loss. (A) Mice were injected for 30 days with tamoxifen to activate and sustain the induction of c-Myc. Random blood glucose measurements showed diabetes development in both $\mathrm{Myc}^{+} \mathrm{Cytc}^{+/+}$and $\mathrm{Myc}^{+} \mathrm{Cytc} \mathrm{KA}^{\mathrm{KA} / \mathrm{KA}}$ mice, $n=5$ per genotype. (B) $\beta$-Cell area per pancreatic area calculated on insulin-stained pancreatic sections showed similar degrees of $\beta$-cell destruction with c-Myc activation in both $\mathrm{Myc}^{+}$ mice compared with $\mathrm{Myc}^{-}$controls, $n=5$ per genotype. Original magnification $\times 10$. Scale bars $=200 \mu \mathrm{m}$. All mice used in experiments were between 8 and 12 weeks of age. Results represent mean \pm s.E.M. ${ }^{*} P<0 \cdot 05$.

increases in Ki67- and TUNEL-positive islet cells between the c-Myc-activated $\mathrm{Myc}^{+} \mathrm{Cytc}^{+/+}$and $\mathrm{Myc}^{+} \mathrm{C} \gamma t \mathrm{c}^{\mathrm{KA} / \mathrm{KA}}$ mice after 2 days of tamoxifen injection (Fig. 6A and B). These results demonstrate that cytochrome $c$ is not required in c-Myc-induced proliferation and apoptosis in pancreatic islets.

Extrinsic apoptotic pathway is also not required for $c-M y c-$ induced $\beta$-cell apoptosis

Given that the cytochrome $c$-mediated intrinsic apoptotic pathway was not required for c-Myc-induced apoptosis, we were interested in examining whether the extrinsic pathway was essential in c-Myc-induced $\beta$-cell apoptosis in vivo. Thus, $\mathrm{M \gamma c}^{+} \mathrm{RIPcre}^{+} \operatorname{Cas} p 8^{\mathrm{f} / \mathrm{fl}}$ mice were generated using a similar strategy as $\mathrm{Mrc}^{+} \mathrm{C} \gamma t^{\mathrm{KA} / \mathrm{KA}}$ mice, through breeding the inducible $\beta$-cell-specific c-Myc transgenic mice with RIPcre ${ }^{+} \operatorname{Casp} 8^{\mathrm{f} / \mathrm{fl}}$ mice.

Mice were injected with tamoxifen daily for 30 days to activate $\mathrm{c}-\mathrm{Myc}$ in the islets as previously shown (Radziszewska et al. 2009). Similar to $\mathrm{Myc}^{+} \mathrm{C}_{t} \mathrm{c}^{\mathrm{KA} / \mathrm{KA}}$ mice, $\mathrm{Myc}^{+}{ }^{\mathrm{R} I P c r e}{ }^{+} \operatorname{Casp} 8^{\mathrm{A} / \mathrm{fl}}$ mice and their wild-type littermates developed diabetes within 3 days of c-Myc activation. Hyperglycemia continued throughout the period of tamoxifen injection without any differences between the two genotypes (Fig. 7A). The pancreatic sections immunostained for insulin at the end of the 30-day injections revealed near-complete islet destruction in the mice of both genotypes (Fig. 7B). The similar progression of diabetes in both $\mathrm{Myc}^{+}$RIPcre $^{+} \mathrm{Casp}^{\mathrm{A} / \mathrm{fl}}$ mice and $\mathrm{Myc}^{+}$RIPcre $^{+}$Casp $8^{+/+}$ littermates indicates that the caspase- 8 -mediated pathway is also not essential for c-Myc-induced $\beta$-cell death.

\section{Discussion}

Cytochrome $c$ released from the mitochondria is an essential component of the intrinsic apoptotic pathway in response to DNA damage and other forms of cellular stress (Parone et al. 2002). However, due to the essential requirement of cytochrome $c$ in mitochondrial respiration, in vivo analysis of cytochrome $c$ in apoptotic signaling was not possible. To circumvent this limitation, a cytochrome $c$ 'knock-in' mouse $\left(C y t c^{\mathrm{KA} / \mathrm{KA}}\right.$ mouse) in which a $\mathrm{K} 72$ allele mutation specifically abolishes the apoptotic function of cytochrome $c$ was generated (Hao et al. 2005). In this model, cytochrome $c$ is released normally from the mitochondria on apoptotic stimuli but is unable to engage with APAF-1 to activate downstream caspase-9 (Hao et al. 2005). This study examined the role of cytochrome $c$-mediated apoptosis in the pancreatic $\beta$-cells and in glucose homeostasis. Surprisingly, no significant defects in glucose metabolism or $\beta$-cell mass were found in $C y t c{ }^{\mathrm{KA} / \mathrm{KA}}$ mice, demonstrating that cytochrome $c$-mediated apoptosis is not essential in modulating pancreatic $\beta$-cell mass.

Mouse embryonic fibroblasts harboring the $C y t c{ }^{\mathrm{KA} / \mathrm{KA}}$ mutation show reduced caspase- 3 activation and were resistant to a variety of apoptotic stimuli including u.v. irradiation, serum withdrawal, or staurosporine (Li et al. 2000, Hao et al. 2005). Moreover, a positive feed forward is proposed to exist between caspase-3 activation and cytochrome $c$ release. This is based on the finding that caspase- 3 cleaves the anti-apoptotic BCL-2 family member BCL-X $\mathrm{L}_{\mathrm{L}}$, which promotes mitochondrial outer membrane permeabilization (Woo et al. 1999, Basanez et al. 2001). In pancreatic $\beta$-cells, the absence of caspase- 3 has been shown to confer protection against STZ- and c-Myc-induced apoptosis (Liadis et al. 2003, Radziszewska et al. 2009). These findings prompted further study on the role of the cytochrome $c$-mediated apoptotic pathway in $\beta$-cell apoptosis. 

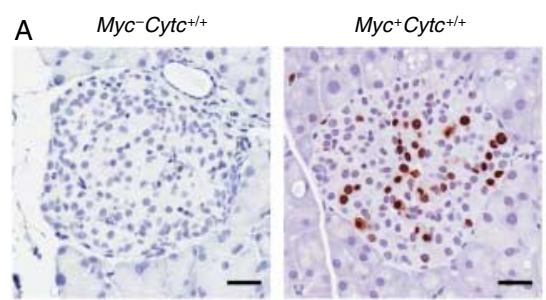

B
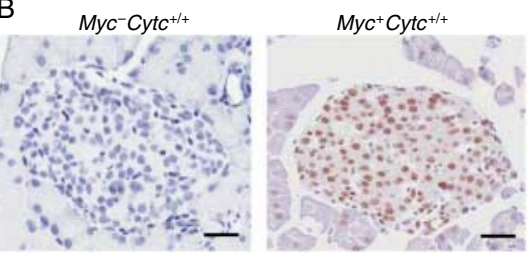

$\mathrm{Myc}^{+} \mathrm{Cy} \mathrm{C}^{\mathrm{KA} / \mathrm{KA}}$

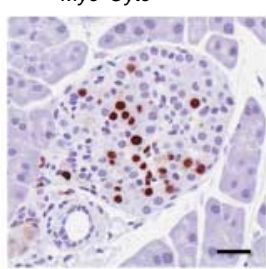

$\mathrm{Myc}^{+} \mathrm{Cytc} \mathrm{KAKA}^{\mathrm{K}}$

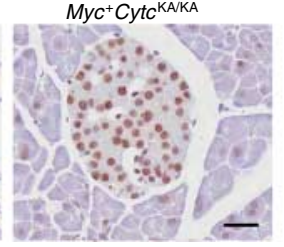

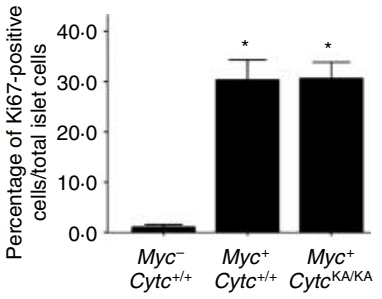

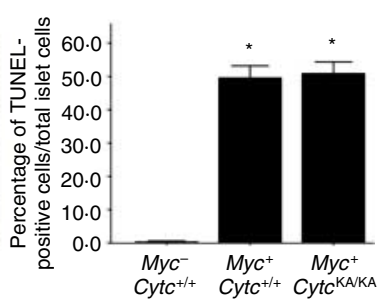

Figure 6 Tamoxifen treatment after 2 days increases islet cell proliferation and apoptosis in both $\mathrm{MyC}^{+} \mathrm{Cytc}^{+/+}$and $\mathrm{Myc}^{+} \mathrm{Cytc}^{\mathrm{KA} / \mathrm{KA}}$ mice. (A) Ki67 immunostaining and (B) TUNEL assay of pancreatic sections showed no differences in islet cell proliferation or apoptosis, respectively, between $\mathrm{Myc}^{+} \mathrm{Cytc}^{+/+}$and $\mathrm{Myc}^{+} \mathrm{Cytc} \mathrm{KA} / \mathrm{KA}^{\mathrm{K}}$ mice, $n=4$ per genotype. Original magnification $\times 20$. Scale bars $=40 \mu \mathrm{m}$. Results represent mean \pm s.E.M. ${ }^{*} P<0 \cdot 05$ compared to untreated controls.

Our results show that loss of the cytochrome $c$-mediated apoptotic pathway did not protect mice from STZ-induced diabetes and $\beta$-cell destruction, which is in contrast to the phenotype observed in mice with $\beta$-cell-specific caspase- 8 deletion, where the mice are protected from STZ-induced $\beta$-cell apoptosis and death (Liadis et al. 2007). Caspase- 3 is known to be the central executioner of apoptosis downstream of both the intrinsic and the extrinsic apoptotic pathways (Lakhani et al. 2006). Mice lacking either caspase-3 or caspase- 8 specifically in the $\beta$-cells were protected against STZ-induced diabetes. Therefore, the lack of protection from mice with defects in the cytochrome $c$-mediated intrinsic apoptotic pathway would suggest that a redundant or compensatory mechanism is in place for intrinsic but not extrinsic apoptotic pathway in $\beta$-cells, at least in response to STZ. Other mitochondrial proteins that are released during apoptosis, including apoptosis-inducing factor, Smac/DIA$\mathrm{BLO}$, endonuclease $\mathrm{G}$, and Omi/HtrA2, have been implicated in various aspects of the cell death process (van Loo et al. 2002). These mitochondrial proteins therefore potentially play redundant roles and compensate for the loss of cytochrome $c$.
A

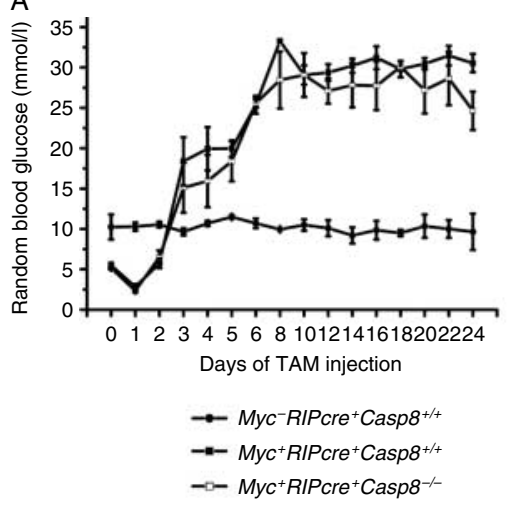

B
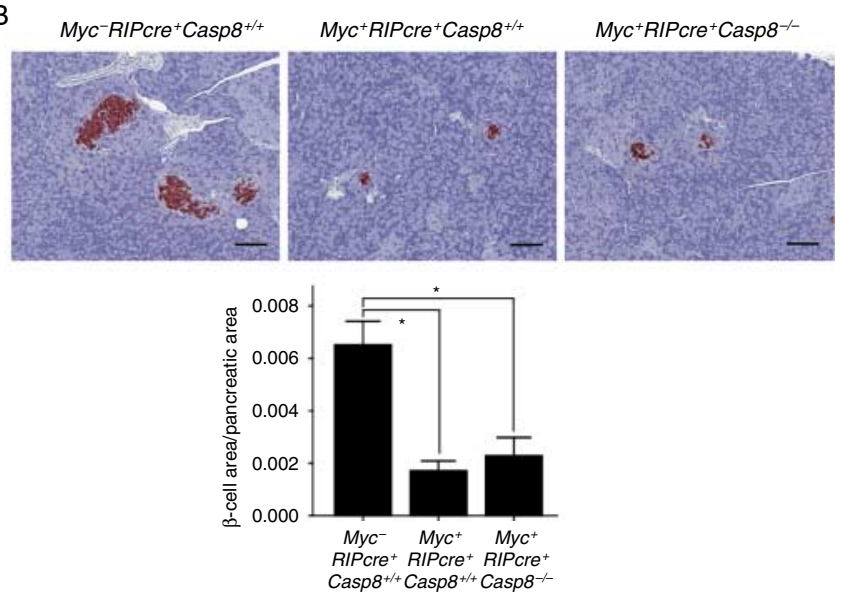

Figure 7 Caspase- 8 deletion in the $\beta$-cells does not protect mice against c-Myc-induced diabetes and $\beta$-cell death. (A) Random blood glucose monitor during 30 days of tamoxifen treatment showed that both $\mathrm{MyC}^{+}$RIPCre $^{+}$Casp $^{+/+}$ and $\mathrm{Myc}^{+}$RIPCre $^{+} \mathrm{Casp}^{\mathrm{fl} / \mathrm{fl}}$ mice developed diabetes, $n=5$ per genotype. (B) $\beta$-Cell per pancreatic area calculated from insulin-stained pancreatic sections showed similar degrees of islet ablation in both Myc ${ }^{+}$genotypes compared with $\mathrm{Myc}^{-}$controls, $n=5$ per genotype. Original magnification $\times 10$. Scale bars $=200 \mu \mathrm{m}$. All mice used in experiments were between 8 and 12 weeks of age. Results represent mean \pm S.E.M. ${ }^{*} P<0 \cdot 05$. 
c-Myc, a proto-oncogene, is a potent inducer of both proliferation and apoptosis but appears to have a predominant pro-apoptotic role in pancreatic $\beta$-cells (Jonas et al. 2001, Laybutt et al. 2002, Pelengaris et al. 2002, Van de Casteele et al. 2003). Activation of c-Myc sensitizes the cell to apoptosis by promoting cytochrome $c$ release from the mitochondria to the cytosol. The molecular mechanisms through which $\mathrm{c}-\mathrm{Myc}$ promotes cytochrome $c$ release from the mitochondria are as yet unclear but are likely through its regulation on the expression, localization, or activity of $\mathrm{BH} 3$ proteins composed of anti-apoptotic (e.g. BCL-2 and BCL- $\mathrm{X}_{\mathrm{L}}$ ) and pro-apoptotic (e.g. BAX and BAK) members. These proteins modulate each others' activities by forming heterodimers that regulate the release of cytochrome $c$ from the mitochondria (Li et al. 2000, Green 2003). In cultured fibroblasts, c-Myc-induced apoptosis was shown to be blocked by microinjection of anti-cytochrome $c$ antibodies by inhibiting the activation of caspase-9 in a cell-free system, suggesting a necessary requirement of cytochrome $c$ for c-Myc-induced cell death (Kluck et al. 1997b). These reports support a critical role of the cytochrome $c$-mediated apoptotic pathway in c-Myc-induced cell death.

Our previous study showed that caspase- 3 deletion confers protection from c-Myc-induced apoptosis in pancreatic $\beta$-cells, suggesting that caspase-3 is required for c-Mycinduced apoptosis (Radziszewska et al. 2009). Given the central role of caspase- 3 in both intrinsic and extrinsic apoptotic pathways, however, it was not known whether the activation of caspase- 3 in this model was through the intrinsic or extrinsic pathway. In order to clarify the signaling pathways that mediate c-Myc-induced apoptosis in the pancreatic $\beta$-cell, we generated mice that have inducible c-Myc activation in the $\beta$-cells with the absence of the cytochrome $c$-mediated apoptotic pathway. We found that loss of the cytochrome $c$-mediated apoptotic pathway did not protect mice from c-Myc-induced $\beta$-cell apoptosis and diabetes.

We then examined the role of extrinsic pathway in c-Mycinduced apoptosis through deletion of its critical mediator, caspase- 8 , in the pancreatic $\beta$-cells. Unexpectedly, blockage of extrinsic pathway also did not protect mice from c-Mycinduced apoptosis and diabetes. Collectively, this study shows that both the intrinsic and the extrinsic pathways may be involved in $\beta$-cell death on $\mathrm{c}-\mathrm{Myc}$ induction; however, the mice lacking either pathway alone are susceptible to c-Mycinduced $\beta$-cell death, suggesting a potential compensatory mechanism to take place in the event of a defect in one of the pathways.

In summary, this study reveals that cytochrome $c$-mediated apoptosis is not required in $\beta$-cell homeostasis, or for STZand c-Myc-induced apoptosis. It appears that for $\beta$-cell apoptosis induced by c-Myc activation, neither cytochrome $c$ nor caspase-8 alone is essential. This likely reflects nature's safety net of redundant mechanisms to avoid catastrophic loss of the potentially limited insulin-producing pancreatic $\beta$-cells.

\section{Declaration of interest}

The authors declare that there is no conflict of interest that could be perceived as prejudicing the impartiality of the research reported.

\section{Funding}

This work was supported by a grant to $\mathrm{M} \mathrm{W}$ from the Canadian Institutes of Health Research (CIHR) MOP-201188 and Canadian Diabetes Association. D C was supported by the CIHR Canada Graduate Scholarship (Doctoral) and the Comprehensive Research Experience of Medical Students Scholar Program at the Faculty of Medicine, University of Toronto.

\section{References}

Basanez G, Zhang J, Chau BN, Maksaev GI, Frolov VA, Brandt TA, Burch J, Hardwick JM \& Zimmerberg J 2001 Pro-apoptotic cleavage products of $\mathrm{Bcl}-\mathrm{xL}$ form cytochrome $c$-conducting pores in pure lipid membranes. Journal of Biological Chemistry 276 31083-31091. (doi:10.1074/jbc. M103879200)

Bruin JE, Gerstein HC, Morrison KM \& Holloway AC 2008 Increased pancreatic beta-cell apoptosis following fetal and neonatal exposure to nicotine is mediated via the mitochondria. Toxicological Sciences : an Official Journal of the Society of Toxicology 103 362-370. (doi:10.1093/toxsci/kfn012)

Chen J, Fontes G, Saxena G, Poitout V \& Shalev A 2009 Lack of TXNIP protects against mitochondria-mediated apoptosis but not against fatty acidinduced ER stress-mediated beta-cell death. Diabetes 59 440-447. (doi:10. 2337/db09-0949)

Donath MY, Ehses JA, Maedler K, Schumann DM, Ellingsgaard H, Eppler E \& Reinecke M 2005 Mechanisms of $\beta$-cell death in type 2 diabetes. Diabetes 54 S108-S113. (doi:10.2337/diabetes.54.suppl_2.S108)

Finegood DT, Scaglia L \& Bonner-Weir S 1995 Dynamics of beta-cell mass in the growing rat pancreas. Estimation with a mathematical model. Diabetes 44 249-256. (doi:10.2337/diabetes.44.3.249)

Green DR 2003 Apoptotic signaling pathways in the immune system. Immunological Reviews 193 5-9. (doi:10.1034/j.1600-065X.2003.00045.x)

Hao Z, Duncan GS, Chang CC, Elia A, Fang M, Wakeham A, Okada H, Calzascia T, Jang Y, You-Ten A et al. 2005 Specific ablation of the apoptotic functions of cytochrome $c$ reveals a differential requirement for cytochrome $c$ and Apaf-1 in apoptosis. Cell 121 579-591. (doi:10.1016/j.cell.2005.03.016)

Holohan C, Szegezdi E, Ritter T, O’Brien T \& Samali A 2008 Cytokineinduced beta-cell apoptosis is NO-dependent, mitochondria-mediated and inhibited by BCL-XL. Journal of Cellular and Molecular Medicine 12 591-606. (doi:10.1111/j.1582-4934.2007.00191.x)

Jacobson MD, Weil M \& Raff MC 1997 Programmed cell death in animal development. Cell 88 347-354. (doi:10.1016/S0092-8674(00)81873-5)

Jonas JC, Laybutt DR, Steil GM, Trivedi N, Pertusa JG, Van de Casteele M, Weir GC \& Henquin JC 2001 High glucose stimulates early response gene c-Myc expression in rat pancreatic beta cells. Journal of Biological Chemistry 276 35375-35381. (doi:10.1074/jbc.M105020200)

Klefstrom J, Verschuren EW \& Evan G 2002 c-Myc augments the apoptotic activity of cytosolic death receptor signaling proteins by engaging the mitochondrial apoptotic pathway. Journal of Biological Chemistry 277 43224-43232. (doi:10.1074/jbc.M206967200)

Kluck RM, Bossy-Wetzel E, Green DR \& Newmeyer DD $1997 a$ The release of cytochrome $c$ from mitochondria: a primary site for Bcl-2 regulation of apoptosis. Science 275 1132-1136. (doi:10.1126/science.275.5303.1132)

Kluck RM, Martin SJ, Hoffman BM, Zhou JS, Green DR \& Newmeyer DD $1997 b$ Cytochrome $c$ activation of CPP32-like proteolysis plays a critical role in a Xenopus cell-free apoptosis system. EMBO Journal 16 4639-4649. (doi:10.1093/emboj/16.15.4639)

Kuwana T, Mackey MR, Perkins G, Ellisman MH, Latterich M, Schneiter R, Green DR \& Newmeyer DD 2002 Bid, Bax, and lipids cooperate to form supramolecular openings in the outer mitochondrial membrane. Cell 111 331-342. (doi:10.1016/S0092-8674(02)01036-X) 
Lakhani SA, Masud A, Kuida K, Porter GA Jr, Booth CJ, Mehal WZ, Inayat I \& Flavell RA 2006 Caspases 3 and 7: key mediators of mitochondrial events of apoptosis. Science 311 847-851. (doi:10.1126/science.1115035)

Laybutt DR, Weir GC, Kaneto H, Lebet J, Palmiter RD, Sharma A \& Bonner-Weir S 2002 Overexpression of c-Myc in beta-cells of transgenic mice causes proliferation and apoptosis, downregulation of insulin gene expression, and diabetes. Diabetes 51 1793-1804. (doi:10.2337/diabetes.51. 6.1793)

Li P, Nijhawan D, Budihardjo I, Srinivasula SM, Ahmad M, Alnemri ES \& Wang X 1997 Cytochrome $c$ and dATP-dependent formation of Apaf-1/ caspase-9 complex initiates an apoptotic protease cascade. Cell 91 479-489. (doi:10.1016/S0092-8674(00)80434-1)

Li H, Zhu H, Xu CJ \& Yuan J 1998 Cleavage of BID by caspase 8 mediates the mitochondrial damage in the Fas pathway of apoptosis. Cell 94 491-501. (doi:10.1016/S0092-8674(00)81590-1)

Li K, Li Y, Shelton JM, Richardson JA, Spencer E, Chen ZJ, Wang X \& Williams RS 2000 Cytochrome $c$ deficiency causes embryonic lethality and attenuates stress-induced apoptosis. Cell 101 389-399. (doi:10.1016/ S0092-8674(00)80849-1)

Liadis N, Murakami K, Eweida M, Elford AR, Sheu L, Gaisano HY, Hakem R, Ohashi PS \& Woo M 2003 Caspase-3-dependent beta-cell apoptosis in the initiation of autoimmune diabetes mellitus. Molecular and Cellular Biology 25 3620-3629. (doi:10.1128/MCB.25.9.3620-3629.2005)

Liadis N, Salmena L, Kwan E, Tajmir P, Schroer SA, Radziszewska A, Li X, Sheu L, Eweida M, Xu S et al. 2007 Distinct in vivo roles of caspase-8 in beta-cells in physiological and diabetes models. Diabetes 56 2302-2311. (doi:10.2337/db06-1771)

Liu X, Kim CN, Yang J, Jemmerson R \& Wang X 1996 Induction of apoptotic program in cell-free extracts: requirement for dATP and cytochrome c. Cell 86 147-157. (doi:10.1016/S0092-8674(00)80085-9)

Lowell BB \& Shulman GI 2005 Mitochondrial dysfunction and type 2 diabetes. Science 307 384-387. (doi:10.1126/science.1104343)

Muzio M, Chinnaiyan AM, Kischkel FC, O'Rourke K, Shevchenko A, Ni J, Scaffidi C, Bretz JD, Zhang M, Gentz R et al. 1996 FLICE, a novel FADDhomologous ICE/CED-3-like protease, is recruited to the CD95 (Fas/APO-1) death-inducing signaling complex. Cell 85 817-827. (doi:10. 1016/S0092-8674(00)81266-0)

O'Brien BA, Harmon BV, Cameron DP \& Allan DJ 1997 Apoptosis is the mode of beta-cell death responsible for the development of IDDM in the nonobese diabetic (NOD) mouse. Diabetes 46 750-757. (doi:10.2337/ diabetes.46.5.750)

Parone PA, James D \& Martinou JC 2002 Mitochondria: regulating the evitable. Biochimie 84 105-111. (doi:10.1016/S0300-9084(02)01380-9)

Pelengaris S, Khan M \& Evan GI 2002 Suppression of Myc-induced apoptosis in beta cells exposes multiple oncogenic properties of Myc and triggers carcinogenic progression. Cell 109 321-334. (doi:10.1016/S00928674(02)00738-9)

Radziszewska A, Schroer SA, Choi D, Tajmir P, Radulovich N, Ho JC, Wang L, Liadis N, Hakem R, Tsao MS et al. 2009 Absence of caspase-3 protects pancreatic $\{$ beta $\}$-cells from c-Myc-induced apoptosis without leading to tumor formation. Journal of Biological Chemistry 284 10947-10956. (doi:10. 1074/jbc.M806960200)
Rodriguez J \& Lazebnik Y 1999 Caspase-9 and APAF-1 form an active holoenzyme. Genes and Development 13 3179-3184. (doi:10.1101/gad.13. 24.3179)

Saini KS, Thompson C, Winterford CM, Walker NI \& Cameron DP 1996 Streptozotocin at low doses induces apoptosis and at high doses causes necrosis in a murine pancreatic beta cell line, INS-1. Biochemistry and Molecular Biology International 39 1229-1236. (doi:10.1080/ 15216549600201422)

Salmena L, Lemmers B, Hakem A, Matysiak-Zablocki E, Murakami K, Au PY, Berry DM, Tamblyn L, Shehabeldin A, Migon E et al. 2003 Essential role for caspase 8 in T-cell homeostasis and T-cell-mediated immunity. Genes and Development 17 883-895. (doi:10.1101/gad.1063703)

Silva JP, Kohler M, Graff C, Oldfors A, Magnuson MA, Berggren PO \& Larsson NG 2000 Impaired insulin secretion and beta-cell loss in tissuespecific knockout mice with mitochondrial diabetes. Nature Genetics 26 336-340. (doi:10.1038/81649)

Thompson CB 1995 Apoptosis in the pathogenesis and treatment of disease. Science 267 1456-1462. (doi:10.1126/science.7878464)

Thomas HE \& Biden TJ 2009 Bad news for $\beta$-cell apoptosis. Diabetes $\mathbf{5 8}$ 1725-1727. (doi:10.2337/db09-0732)

Van de Casteele M, Kefas BA, Cai Y, Heimberg H, Scott DK, Henquin JC, Pipeleers D \& Jonas JC 2003 Prolonged culture in low glucose induces apoptosis of rat pancreatic beta-cells through induction of c-myc. Biochemical and Biophysical Research Communications 312 937-944. (doi:10. 1016/j.bbrc.2003.11.013)

Van Loo G, Saelens X, van Gurp M, MacFarlane M, Martin SJ \& Vandenabeele P 2002 The role of mitochondrial factors in apoptosis: a Russian roulette with more than one bullet. Cell Death and Differentiation 9 1031-1042. (doi:10.1038/sj.cdd.4401088)

Woo M, Hakem A, Elia AJ, Hakem R, Duncan GS, Patterson BJ \& Mak TW 1999 In vivo evidence that caspase- 3 is required for Fas-mediated apoptosis of hepatocytes. Journal of Immunology 163 4909-4916.

Woo M, Hakem R \& Mak TW 2000 Executionary pathway for apoptosis: lessons from mutant mice. Cell Research 10 267-278. (doi:10.1038/sj.cr. 7290054)

Yang J, Liu X, Bhalla K, Kim CN, Ibrado AM, Cai J, Peng TI, Jones DP \& Wang X 1997 Prevention of apoptosis by Bcl-2: release of cytochrome $c$ from mitochondria blocked. Science 275 1129-1132. (doi:10.1126/science. 275.5303.1129)

Zimmermann KC, Bonzon C \& Green DR 2001 The machinery of programmed $\beta$-cell death. Pharmacology and Therapeutics 92 57-70. (doi:10. 1016/S0163-7258(01)00159-0)

Zou H, Li Y, Liu X \& Wang X 1999 An APAF-1.cytochrome $c$ multimeric complex is a functional apoptosome that activates procaspase-9. Journal of Biological Chemistry 274 11549-11556. (doi:10.1074/jbc.274.17.11549)

Received in final form 3 June 2011

Accepted 30 June 2011

Made available online as an Accepted Preprint 30 June 2011 